
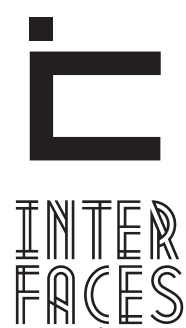

CIENTÍFICAS

EDUCAÇ̃̃o

\title{
A HISTORIOGRAFIA DA FUNDACÃ̃ DA FACULDADE DE MEDICINA DE SERGIPE: O QUE DIZ AS FONTES
}

Patricia de Sousa Nunes Silva ${ }^{1}$

\section{RESUMO}

Pesquisadores e historiadores da Educação vêm ampliando seus olhares quanto à necessidade de estudar instituições escolares, mergulhando em seu universo interior. Neste sentido, o presente trabalho tem por objetivo desvelar historicamente a fundação e implantação da Faculdade de Medicina de Sergipe que, através de sua fundação em 1960, pelo médico, político e professor Antonio Garcia Filho, propiciou a instalação da Universidade Federal de Sergipe. Apoiando-nos metodologicamente na pesquisa documental e bibliográfica, procuramos apresentar o contexto histórico do ensino superior em Sergipe bem como as dificuldades operacionais e políticas da época que permearam os caminhos de Garcia Filho para a fundação da Faculdade de Medicina de Sergipe. Tornou-se um colaborador da educação,
Raylane Andreza Dias N. Barreto²

agindo como um dos mais importantes agentes formadores da intelectualidade e contribuindo para a história da educação em Sergipe. A luz do conceito de intelectuais proposto pelo francês Jean François Sirinelli (1996), foi possível perceber que, com a fundação da Faculdade de Medicina de Sergipe, Garcia Filho desempenhou importante papel na educação do Estado além de alcançar um dos principais objetivos almejados pelo grupo médico de Sergipe: a necessidade de formar médicos para atender a classe popular desassistida do estado.

\section{PALAVRAS-CHAVE}

Antonio Garcia Filho. Educação. Faculdade de Medicina de Sergipe. Intelectual. 


\section{ABSTRACT}

Investigators and historians of education have broadened their gaze on the need to study educational institutions, dipping into their inner universe. In this sense, this paper aims to uncover, historically, the foundation and establishment of the Medicine College of Sergipe, which, through its founding in 1960, by the doctor, politician and professor Antonio Garcia Filho, led to the installation of the Federal University of Sergipe. Relying on archival and literature research, it was presented the historical context of higher education in Sergipe and the operational and political difficulties of the period in which Garcia Filho founded the Medical College of Sergipe. He became an educational collaborator, acting as one of the most important people who formed intellectuals in Sergipe and contributing to the history of education in Sergipe. Based on the concepts of the French intellectual Jean Francois Sirinelli (1996), it was possible to notice that, through the Medicine College of Sergipe, Garcia Filho played an important role in the education of the State, besides achieving a major goal pursued by the medical group of Sergipe, the necessity to train physicians to assist the unattended popular class of the state.

\section{KEYWORDS}

Antonio Garcia Filho. Education. Medical College of Sergipe. Intellectual.

\section{INTRODUÇ̧̃̃O}

Sob os auspícios da História Cultural, os historiadores da educação vêm ampliando seus olhares para a exploração de novas fontes a fim de fornecer um caminho seguro para incursionarem seu território e aventurar-se no desvelamento de sua historia. Con-

\section{RESUMEN}

Los investigadores e historiadores de la educación han ampliado su mirada en la necesidad de estudiar las instituciones educativas, inmersos en su universo interior. En este sentido, este trabajo tiene como objetivo descubrir la historia de la fundación y establecimiento de la Facultad de Medicina de Sergipe, que, a través de su fundación en 1960 por el médico, político y profesor Antonio García Filho, llevó a la instalación de la Universidad Federal de Sergipe. Apoyándose en las investigaciones de archivo y la literatura metodológica, el trabajo presenta el contexto histórico de la educación superior en Sergipe y las dificultades operativas y políticas que enfrentó García Filho para la fundación de la Facultad de Medicina de Sergipe en la época. Se convirtió en un colaborador de la educación, actuando como uno de los más importantes agentes de formación de intelectualidad contribuyendo a la historia de la educación en Sergipe. A la luz del concepto de intelectual propuesto por el francés Jean Francois Sirinelli (1996), se reveló que, con la fundación de la Facultad de Medicina de Sergipe, García Filho desempeñó un papel importante en la educación del Estado además de lograr un objetivo principal deseado por el grupo médico de Sergipe: la necesidad de formar a los médicos para atender a las clases populares desatendidas por el estado.

\section{PALABRAS CLAVE:}

Antonio García Filho. Educación. Facultad de Medicina de Sergipe. Intelectual.

siderada uma linha metodológica, apresenta características como a valorização da relação da história com outras ciências sociais; abrangência de todos os aspectos da vida social e humana, a exemplo das mentalidades coletivas, da morte, da infância, da mulher, do 
corpo, dos gestos, dentre outros; ampliação da noção de fonte para além dos documentos oficiais; questionamento do conteúdo dos documentos, uma vez que são produtos do homem suscetíveis aos entraves e aos interesses da memória. No entanto, é através das interrogações feitas às fontes que podemos interpretar e reler o passado para compreender o presente. Levando-se em consideração, portanto, esses aspectos, Burke (1992) afirma que "[...] o que era agora considerado uma coisa imutável é agora encarado como uma 'construção cultural', sujeita a variações, tanto no tempo quanto no espaço. [...] A base filosófica da nova história é a ideia de que a realidade é social ou culturalmente construída" (BURKE, 1992, p. 11).

Em Sergipe, a partir da década de 1990, mais precisamente com a criação do mestrado em educação da Universidade Federal de Sergipe, um número significativo de pesquisadores e historiadores sergipanos despertaram maior interesse e mobilização na produção de estudos da História da Educação em Sergipe. No rol dos objetos de pesquisa encontram-se os intelectuais da educação, impressos católicos e protestantes, a formação de professores, de disciplinas escolares, livros didáticos, formação de uma elite intelectual, organização escolar, políticas educacionais, Estado e Educação, educação e sociedade bem como instituições educativas.

Neste sentido, o presente artigo se propôs a compreender a memória histórica da Faculdade de Medicina de Sergipe, desde sua fundação até a sua implantação, através da análise e interpretação de sua massa documental. Para tanto, recorremos a fontes tais como livros, revistas, jornais, regulamentos, fotos, cartas, ofícios, dentre outros documentos depositadas em instituições como as bibliotecas da Universidade Tiradentes e da Universidade Federal de Sergipe, da Biblioteca Pública Epifânio Dória e do Instituto Tobias Barreto de Educação e Cultura, do Arquivo Geral da universidade Federal de Sergipe, onde foi encontrada grande parte da documentação referente à fundação e funcionamento da Faculdade de Medicina de Sergipe.
Com o objetivo de desvelar sua história recorremos à pesquisa bibliográfica, aos pressupostos da História Cultural, ao conceito de intelectuais proposto pelo francês Jean François Sirinelli (1996) e ao conceito de instituição educativa de Magalhães (2004). Esses conceitos estão presentes em estudos da História Cultural, os quais vêm dando subsídios aos trabalhos em história da educação brasileira, inclusive aos estudos históricos em Sergipe. Assim sendo, quanto ao fundador da Faculdade de Medicina, o considero como intelectual na acepção do francês Jean François Sirinelli, que remete o termo a uma questão de qualidade humana, existindo um caráter polimorfo e polifônico, ou seja, de compreensão e de extensão da noção, que podem recair em dois significados do intelectual, uma ampla e sociocultural, englobando os criadores e os mediadores culturais e a outra mais estreita, baseada na noção de engajamento (SIRINELLI, 1996). Portanto, para Sirinelli (1997), a noção de intelectual criador e mediador recai em uma definição empírica de um homem de cultura, enquanto "[...] à primeira categoria pertencem os que participam na criação artística e literária ou no progresso do saber, na segunda juntam-se os que contribuem para difundir e vulgarizar os conhecimentos dessa criação e desse saber”. (SIRINELLI, 1997, p. 261).

Em relação ao segundo conceito abordado nesta pesquisa, qual seja a de instituição educativa, buscarei a identidade cultural e educacional da Faculdade de Medicina de Sergipe, pois, segundo Magalhães (2004, p. 147) “[...] a história de uma instituição educativa traduz-se na construção de uma identidade cultural e educacional, que resulta da articulação do itinerário histórico com o modelo educacional”. Assim, no que diz respeito aos espaços sociais destinados aos processos de ensino e de aprendizagem, ou seja, as instituições, Magalhães revela que:

\footnotetext{
A história de uma instituição educativa inicia-se pela reinterpretação dos historiais anteriores, das memórias e do arquivo, como fundamento de uma identidade histórica. Esta identidade implica ainda, para além da internalidade, a inscrição num quadro sociocultu-
} 
ral e educacional mais amplo, constituído pela rede de instituições congêneres e pelo sistema educativo. (MAGALHÃES, 2004, p. 147).

Desta forma, para compreender a identidade histórica da Faculdade de Medicina de Sergipe, que fora formada em um contexto sociocultural e educacional especifico, faz-se necessário que compreendamos seus "historiais anteriores", a fim de que consigamos chegar o mais próximo possível de sua criação porque, apesar das fontes nos mostrarem que, na década de 50, durante o governo de Dr. Arnaldo Garcez (19511955), houve uma tentativa de fundar uma Faculdade de Medicina, a historiografia mostra que, apenas em 1961, esta foi concretizada pelo médico, político e educador Antonio Garcia Filho e de outros colegas atuantes na saúde em Sergipe. A essa época, seu irmão, o bacharel em direito e promotor Luiz Garcia, ocupava o cargo de Governador do Estado.

Conceber a Faculdade de Medicina como uma instituição educativa que pode ser reinterpretada a partir de suas memórias é entendê-la como possuidora de uma identidade própria focada na formação de médi- cos, cujo objetivo era melhorar o quadro educacional do Estado de Sergipe além de ampliar o atendimento médico na rede hospitalar. É relevante citar, ainda, que a fundação da Faculdade de Medicina de Sergipe propiciou a instalação da Universidade Federal de Sergipe.

Além da fundação da Faculdade de Medicina de Sergipe, Antonio Garcia Filho também esteve à frente de várias instituições no Estado vinculadas à área da medicina. Como exemplo, temos o Conselho Regional de Medicina; a atual UNIMED, a Sociedade de Anestesiologia do Estado de Sergipe (SAESE); fundou também, a época, o terceiro Centro de Reabilitação do país denominado de "Ninota Garcia”. Ele também exerceu a função de professor em todas as cinco faculdades existente no estado no período de 1948 a 1968, São elas: Faculdade de Química de Sergipe, Faculdade de Economia de Sergipe, Faculdade de Filosofia de Sergipe, Faculdade de Direito de Sergipe e Faculdade de Odontologia de Sergipe, além da Faculdade de Medicina de Sergipe, de onde foi nomeado o primeiro Pró-Reitor de Extensão e Assuntos Comunitários.

\section{CONTEXTO HISTÓRICO DA EDUCAÇÃO SUPERIOR EM SERGIPE}

\subsection{DAS FACULDADES ISOLADAS À UNIVERSIDADE FEDERAL DE SERGIPE}

Apesar de administrados por políticos de nível superior, Sergipe teve poucos governantes envolvidos com a questão da cultura e com os olhos lançados no futuro, visando formar quadros, apostando no investimento intelectual para atender as diversas funções requeridas por um Estado em vias de desenvolvimento. Sergipe, portanto, ganha o seu primeiro curso superior em 1913, quando foi fundado o Seminário
Diocesano, que tinha, dentre outras incumbências, a de formar os seus alunos bacharéis em Ciências Eclesiásticas. Segundo Jackson da Silva Lima: “Com a primeira turma de formandos em humanidades, o Seminário Diocesano foi compelido a introduzir as chamadas Aulas Maiores, equivalentes ao curso superior (Ciências Eclesiásticas)" (LIMA, 1995, p. 94). Ainda que o Seminário Diocesano em Aracaju assumisse tal 
papel, o Estado não concedia aos seus alunos outra oportunidade. O Curso de Ciências Eclesiásticas não supria a demanda do Estado. Mesmo porque Sergipe crescia e com ele suas necessidades, dentre elas a de profissionais que pudessem dar ao seu Estado um maior status. 0 que acontecia era que dezenas de rapazes sergipanos, de todos os pontos do Estado, tomavam aulas preparatórias no Atheneu Sergipense e iam fazer seus estudos na Faculdade de Direito do Recife e de Medicina, na Bahia, dentre outras, retirando-se do Estado os possíveis propulsores do progresso.

Sergipe, portanto, conviveu muito tempo com a carência de escolas que pudessem atender aos interesses de sua população até porque o Estado estava crescendo e com ele sua economia. Com o processo de industrialização em ascensão e a falta de profissionais para atender a demanda de mercado, principalmente para ocupar os cargos de administradores, de contadores, de técnicos agrícolas, de bacharéis, de médicos e de professores, Sergipe, em 1943, cria o curso de Administração e finanças com propósito de formar administradores para gerenciar as finanças do Estado e da iniciativa privada e assim suprir com a mais importante das carências de um Estado em desenvolvimento. Mais adiante, em 1947, foi criada a Faculdade de Ciências Econômicas de Sergipe visando prover a carência da mão-de-obra especializada e as limitações dos quadros técnicos para desenvolver e acompanhar as mudanças econômicas e sociais que 0 Estado vinha passando.

No entanto, ainda na década de quarenta, época de maior significação para a modernização industrial e avanços tecnológicos no Brasil decorrente da $2^{\text {a }}$ guerra mundial, o governador de Sergipe, José Rollemberg Leite, funda a Faculdade de Química de Sergipe objetivando formar profissionais capazes de promover e estimular o desenvolvimento industrial do Estado além de apoio aos empreendedores sergipanos na luta para enfrentar a competitividade dos outros estados que avançavam tecnologicamente e teriam que se industrializar também para concorrer ao mercado exportador. A autorização para instalação do Curso de Química Industrial foi concedida em 1949 e em 1950 estava funcionando a Escola de Química de Sergipe e, dessa forma, o Estado contava com mais uma necessidade suprida.

Em 1950 um grupo de intelectuais se reuniu para discutir acerca da necessidade de uma Faculdade de Direito alegando carência de bacharéis para a magistratura, para o Ministério Público e para a advocacia, além de quererem prover o Estado de bacharéis/intelectuais que iriam cooperar com o desenvolvimento Cultural de Sergipe. Providenciada toda a estrutura física e burocrática para o funcionamento da Faculdade de Direito, o próximo passo seria a autorização para seu funcionamento que, por sua vez, fora conseguido no dia 19 de janeiro de 1951, pelo decreto de $n$. ○ 29. 181, também no governo de José Rollemberg Leite. Com isso, a Faculdade de Direito de Sergipe estava pronta para cumprir com seu papel social: levando o Direito e fazendo justiça a todos os sergipanos.

Após a segunda Guerra Mundial, em meio ao clima de efervescência cultural e tecnológica calcadas na modernidade, surge, então, atendendo aos apelos da Igreja Católica e da comunidade sergipana, a Faculdade de Filosofia, que tinha como um dos principais objetivos a formação de professores. O funcionamento da Faculdade foi autorizado pelo Presidente da República, Getúlio Vargas, através do Decreto n. ${ }^{\circ} 20.311$ de 23 de fevereiro de 1951, sendo que este decreto autorizava os cursos de Geografia e História, Letras Anglo-Germânicas, Pedagogia e Matemática, que deveriam ser oferecidos pela Faculdade Católica de Filosofia.

Aproveitando a época de investimento institucional e valorização intelectual, surge a necessidade de implantação do curso de Serviço Social. Embora a faculdade fosse de iniciativa da Igreja, o Estado, mais uma vez (só que agora, na pessoa do governador Arnaldo Rollemberg Garcez), viabilizou sua implantação doando-lhe um prédio. Nascimento e Galgane (1999) deixam clara a importância do curso de Serviço So- 
cial para o Estado, já que Sergipe apresentava, àquela época:

[...] um pluripartidarismo e a disputa pelo poder; e do ponto de vista social, o desemprego, a migração do campo para a cidade, o processo acelerado de urbanização, a elevação do custo de vida, a desigualdade social formavam as principais questões sociais presentes no cenário de Aracaju àquela época. A intervenção na área social estava sob a responsabilidade de instituições vinculadas ao Estado, à Igreja e à iniciativa privada. (NASCIMENTO; GALGANE, 1999, p. 32)

Assim sendo, a implantação desse curso levou mais segurança à comunidade sergipana, que acreditava na atuação desses profissionais para a solução, mesmo que em longo prazo, dos problemas sociais apontados pelos autores supramencionados. A Escola foi reconhecida pelo Governo Federal mediante Decreto n. ${ }^{\circ} 38.413$ de 26 de dezembro de 1955 e o reconhecimento do curso pelo MEC ocorreu dia 05 de janeiro de 1956 pelo Decreto Lei n. ${ }^{0} 3.413$.

\subsection{A FUNDAÇ̃̃O DA FACULDADE DE MEDICINA DE SERGIPE}

Apesar de o século XX ser caracterizado como uma época de modernização, progresso e civilização no Brasil, em que a população passa a mudar seus hábitos, costumes e comportamentos, Sergipe passava por uma crise na área da saúde pública. Entre 1902 e 1927, milhares de sergipanos morreram em virtude de moléstias como a varíola, as epidemias de febre amarela, malária, peste bubônica além de febres intestinais. Assim, através dos trabalhos dos Inspetores de Saúde, que apontaram como determinante das várias afecções mórbidas “[...] a má qualidade da água potável; a precariedade da alimentação; as emanações miasmáticas dos poços, charcos e alagadiços; e os eflúvios deletérios dos corpos em putrefação", conforme apontado por Santana (1997, p. 68), o governo adotou algumas medidas na tentativa de melhorar o quadro como a realização de várias obras de saneamento na capital, drenando
Por fim, completando o quadro das faculdades isoladas que compunham o ensino superior em Sergipe, fora criada e implantada a Faculdade de Medicina. A ideia surgiu em uma das reuniões ocorridas no Centro de Estudos do Hospital de Cirurgia. No dia 12 de junho de 1953, um grupo de médicos resolveu fundar a entidade Sociedade Civil Faculdade de Medicina de Sergipe a fim de arrecadar fundos para a fundação da Faculdade. 0 movimento contou com o apoio do Governador Luiz Garcia, que criou a Secretaria de Educação, Cultura e Saúde e nomeou seu irmão, Dr. Antonio Garcia Filho, que ficou à frente da fundação e a dirigiu até a sua incorporação pela Universidade Federal de Sergipe. No dia 12 de novembro de 1960, a Comissão de Ensino Superior solicitou ao MEC, através do Parecer $n^{\circ} 679$, autorização para o devido funcionamento da Faculdade que, fundada em 1961, obteve seu reconhecimento apenas em setembro de 1966 através do Decreto n. ${ }^{\circ}$ 59.226, ano de formatura da primeira turma da faculdade.

valas, aterrando pântanos e quintais alagados, tratando das fontes, poços e cisternas, dentre outras. (SANTANA, 1997)

A melhoria na área da saúde em Sergipe começou a evoluir com a fundação do Hospital de Cirurgia, inaugurado em maio de 1926, caracterizado como um complexo hospitalar de grande repercussão e importância social. Tal Hospital passou a ser considerado um local de reunião pelos médicos para debates e discussões buscando o avanço do conhecimento científico e tecnológico na área da saúde. Além disso, com suas modernas instalações e métodos, foi possível realizar operações cirúrgicas mais delicadas. Vale ressaltar que, em virtude de sua infraestrutura, foi criado dentro de suas instalações a Escola de Auxiliar de Enfermagem, o curso de odontologia e a futura Faculdade de Medicina. 
Até o final do século XIX e nas primeiras décadas do século XX, os brasileiros que almejassem cursar medicina teriam de se deslocar para a Faculdade de Medicina da Bahia e a do Rio de Janeiro. O Brasil dependia apenas dessas duas Faculdades para formar os médicos sergipanos. A economia de Sergipe, portanto, estava calcada na indústria da cana-de-açúcar e na pecuária. Com o intuito de conquistar status socioeconômico, os filhos dos senhores de engenhos começaram a migrar para estas duas cidades além do Recife, para cursar Medicina ou Direito. Naquela época, havia poucos médicos em Sergipe exercendo a função, fato explicado pela dificuldade em cursar a faculdade, pela forma de pagamento da prestação de seus serviços à comunidade, a falta de clínicas particulares e as dificuldades da classe médica em sustentar sua família com os proventos recebidos. (SILVA, 2006).

A ideia de uma Faculdade de Medicina em Sergipe aflora em 1951 pelo Dr. João Batista Perez Garcia Moreno e o Dr. Benjamin Carvalho, período em que Dr. Rollemberg Garcez (1951-1955) ocupava o cargo de governador do Estado. Logo, despertou olhares da classe médica sergipana para essa necessidade, mas o projeto não saiu do papel. Na perseverança da realização da Faculdade e com o intuito de viabilizar o projeto, alguns médicos fundam, em 1954, a Sociedade Civil Faculdade Medicina de Sergipe, uma entidade governamental sem fins lucrativos, estando o Dr. Augusto Leite à frente da presidência (SILVA, 2006).

Segundo Conde Garcia (2008), o objetivo da classe médica em fundar essa entidade governamental era instalar e manter uma escola de Medicina em Sergipe. No entanto, apesar de a ideia ter sido bem aceita pela população, o projeto ficou apenas na fase de aprovação e registro dos Estatutos da referida Fundação, mesmo com a sensibilização do governador Arnaldo Garcez. Através da Portaria no 3, publicado no Diário Oficial do Estado, edição n. 11.876 de 15 de setembro de 1954, o Governador Arnaldo Rollemberg Garcez colocou à disposição da Sociedade Civil os laboratórios do Instituto Parreiras Horta, do Instituto de Tecnologia e Pesquisas, do departamento de Saúde Pública, do Colégio Estadual de Sergipe e do Serviço de Assistência a Psicopatas. No entanto, segundo Ednaldo Garces (2011, p. 14), “[...] a coisa não prosperou, talvez em função de disputas acirradas entre os dois maiores partidos políticos de então, a UDN, de oposição e o PSD, da situação".

Somente na eleição seguinte de 1959, quando a coligação PSD/PR é novamente derrotada, elegendo-se para o governo de Sergipe o Dr. Luiz Garcia (19591962) do partido UDN, a Faculdade de Medicina deixa de seu uma ideia e passa a ser uma realidade. 0 então Governo de Sergipe criou a Secretaria de Estado da Educação, Cultura e Saúde e convidou ser irmão, Antonio Garcia Filho, a assumir o cargo. Foi com o apoio de Antonio Garcia que a Faculdade se tornou uma realidade (CONDE GARCIA, 2008). A indicação de seu nome para ocupar a secretaria não agradou a muitos, pois, conforme afirma Ednaldo Garces (2011), “A princípio, Antonio Garcia Filho ficou à margem do governo, pois a indicação de seu nome sempre esbarrava nas restrições impostas por lideranças da UDN, por sua história socialista” (GARCES, 2011, p. 14).

Quando Antonio Garcia chegou ao cargo de Secretário, o Estado de Sergipe contava com cinco Instituições superiores: a Faculdade de Química e a Faculdade de Ciências Econômicas e Contábeis, ambas mantidas pelo Estado de Sergipe; a Faculdade de Filosofia e Letras e a Faculdade de Serviço Social, ambas privadas mantidas pela Igreja Católica, e a Faculdade de Direito mantida pelo Governo Federal.

No entanto, o Secretário de Estado da Educação, Cultura e Saúde percebeu que faltava uma sexta escola superior para que Sergipe pleiteasse uma Universidade. No entanto, conforme afirma seu filho Conde Garcia, "Médico devotado, clínico e anestesiologista de renome, logo tomou como prioridade para a sua gestão [...], a criação da Faculdade de Medicina de Sergipe. Para isso dispunha de talento, vontade e força política" 
(CONDE GARCIA, 2008, p. 35). Neste período, Antonio Garcia também era Presidente da Sociedade Médica de Sergipe, que muito facilitou e contribuiu para agilizar o processo da fundação da Faculdade. 0 fato de o Dr. Benjamin Carvalho, amigo de Antonio Garcia e do Governador, ter sido presidente da Sociedade Civil Mantenedora da Faculdade de Medicina e "[...] por sua habilidade em tratar problemas e por sua maneira polida e culta" também contribuiu muito para agilizar este processo (CONDE GARCIA, 2008, p. 36).

Apesar das dificuldades, o Secretário de Estado da Educação, Cultura e Saúde entendeu que aquele era o momento ideal para a realização do suntuoso projeto, justamente pelo fato do apoio decisivo do Governo do Estado, seu irmão Luiz Garcia, e os demais colegas e facilitadores a exemplo dos médicos Benjamin Carvalho, Lourival Bomfim, Walter Cardoso e Lauro Porto.

Mais um passo foi dado. Com a preocupação de preparar e mobilizar a sociedade para a Faculdade de Medicina, Antonio Garcia criou, com o apoio do Núcleo Estudantil Pró-Universidade de Sergipe (NEPUS), o primeiro curso preparatório para vestibular do Estado e assim o denominou de Curso Pré-Vestibular "Dr. Oscar Nascimento". Atuou como um dos professores, lecionando a disciplina de Química e ainda conseguiu a visita de um emissário do Ministério da Educação à então referida Instituição. Conde Garcia (2008) enfatiza a importante atuação de seu pai para a fundação da Faculdade:

[...] não se furtou em colaborar para preparar a juventude do seu Estado, a fim de que ela pudesse usufruir a Faculdade de Medicina que decidira criar. Como se não bastassem suas atribuições de gestor publico e de médico com grande clientela, Antonio Garcia Filho ministrou aulas de Química no citado curso pré-vestibular. Aliou-se aos seus diletos amigos Lourival Bomfim e Hercílio Cruz, também conscientes da importância social e histórica do processo em que estavam envolvidos, e prepararam uma plêiade de jovens talentosos que depois vieram a se formar pela Faculdade de Medicina de Sergipe. (CONDE GARCIA, 2008, p. 39).

Antonio Garcia Filho sugeriu ao governo do Estado a construção de um prédio próximo ao Instituto Par- reiras Horta com o objetivo de sediar, com brevidade, mas provisoriamente, a faculdade de Medicina de Sergipe. 0 prédio contava com três salas para aulas teóricas e uma sala para o ensino da Anatomia. Além disso, Luiz Garcia colocou à disposição da Faculdade os laboratórios de Bioquímica e de Microbiologia do referido Instituto, bem como autorizou o uso das facilidades disponíveis na Escola de Química e no Centro de Saúde da Clínica Psiquiátrica Adauto Botelho. Depois de três anos de funcionamento da Faculdade nas dependências do Instituto Parreiras Horta, a Faculdade de Medicina migrou para o Hospital de Cirurgia, permanecendo ali por mais de vinte anos.

Vale ressaltar que a Faculdade de Medicina não usufruía gratuitamente das dependências deste hospital, sendo o governo do Estado responsável pelo pagamento do aluguel das áreas utilizadas através das verbas destinadas para cobrir as despesas que o ensino exigia. E, assim, através da atuação política do governador Luiz Garcia e do Secretário Antonio Garcia, a Faculdade deixa de ser um sonho e passa a ser uma realidade tão almejada pelos sergipanos. Quanto à atuação de ambos os dirigentes políticos e a fundação da Faculdade, Garces (2011), afirma que: “[...] a Faculdade nasceu porque Antonio Garcia soube conquistar o apoio do seu irmão Governador Luiz Garcia. Soube transformar a quimera, o letárgico sonho, numa firme decisão de governo" (GARCES, 2011, p. 15).

As fontes nos mostram que Antonio Garcia Filho tornou-se personagem principal na história da Faculdade de Medicina de Sergipe contribuindo com a educação e o desenvolvimento social do Estado. Ainda referente à fundação da referida Instituição educativa, Conde Garcia, seu filho, afirma que:

[...] Antonio Garcia Filho foi além do sonho. Ele foi seu FUNDADOR, aquele que realmente concretizou a idéia de se ter uma escola desse porte. Por isso, merece ser reconhecido como tal. É verdade que contou com a ajuda de amigos e idealistas, mas se não foi ele o primeiro a pensar na faculdade, foi dele que brotou a atitude, o trabalho e a persistência para que a obra nascesse. 
'Deus quer, o homem sonha e a obra nasce, conforme Fernando Pessoa'. (CONDE GARCIA, 2008, p. 46).

As dificuldades estavam só começando. 0 desafio agora era o ensino das ciências básicas na Faculdade e montar e preparar o quadro docente. Assim, de acordo com a Ata da sessão ordinária do Conselho Técnico e Administrativo da Faculdade de Medicina de Sergipe, datado de 1960, ficou deliberado que Antonio Garcia e seus colegas Lourival Bomfim e Volmer Bomfim fariam cursos de preparação para professores em Universidades fora do Estado, a citar a Faculdade de Medicina da Bahia e, até mesmo, numa Universidade americana. Antonio Garcia preparou-se para lecionar a disciplina de Bioquímica enquanto Lourival Bomfim ficou com o ensino da biofísica e Volmer Bomfim com Farmacologia. Outros colegas aceitaram o desafio a fim de completar o quadro docente enquanto outras disciplinas eram ministradas por professores convidados de outras Universidades, inclusive do exterior. Por exemplo, conforme mencionado na Ata de reunião da Congregação da Faculdade de Medicina de Sergipe, realizada no dia 19 de janeiro de 1962, podemos citar o professor Silvano Isquerdo Laguna da Universidade de Valladolid, Espanha, que ministrou aulas de Anatomia Humana.

Em 21 de janeiro de 1960, de acordo com Ata do Conselho Técnico e Administrativo da Faculdade de Medicina de Sergipe, foi eleita a primeira Diretoria da Faculdade sendo Dr. Antonio Garcia Filho nomeado ao cargo como o primeiro Diretor da Instituição; Dr. Osvaldo da Cruz Leite, Dr. João Conrado Guerra e Dr. Antero Pales Carozo ocuparam o cargo de Conselho Técnico; os Secretários Alberto Santos Bragança de Azevedo, logo substituído por Bento Alvino Carvalho; os Auxiliares Jairo Fontes Sampaio e José Moreira Alves e o Bibliotecário Eduardo Antonio Conde Garcia.

Finalmente, em 1961, na pessoa do Presidente da República Juscelino Kubitschek, através do Decreto $N^{0} 49.864$ de 11 de janeiro, foi autorizado o pleno funcionamento da Faculdade de Medicina de Sergipe, com sua publicação no Diário Oficial da União em 12 de janeiro do mesmo ano. Ressaltando, portanto, a importância dessa Instituição, Conde Garcia (2008) encerra sua obra recitando um texto, fruto de um ofício-circular em fevereiro de 1968, encaminhado por Antonio Garcia Filho ao Presidente da Fundação do Ensino Médico ao final dos seus oito anos de mandato como Diretor da Faculdade de Medicina de Sergipe em que: "A vitória é dupla: A Faculdade de Medicina de Sergipe como realidade irreversível e, por causa dela, a instalação da Universidade Federal de Sergipe" (CONDE GARCIA, 2008, p. 113).

Nesse mesmo sentido, Garces (2011) discorre acerca da importância da atuação desse intelectual sergipano quando afirma:

Estava consolidado um sonho de longo tempo, e o Dr. Antonio Garcia Filho se tornou, por sua dedicação, esforço, liderança e pela sua privilegiada posição social e política na sociedade sergipana, a mais importante figura na criação da Faculdade de Medicina, removendo com grande esforço todos os obstáculos e realizando o grande sonho dos sergipanos. (GARCES, 2011, p. 15).

Antonio Garcia Filho também discorre, em seu livro "Um pensamento na praça”, sobre a criação da Faculdade, o apoio que teve de seu irmão Luiz Garcia e de colegas, das dificuldades e injustiça que passou durante esse percurso. Dedicou um capítulo de sua obra à Faculdade de Medicina, onde relata:

\begin{abstract}
Em fins do ano de 1959, com a Sociedade Mantenedora sob a presidência do Dr. Benjamin Alves de Carvalho, transmiti ao ilustre médico o pensamento do Governador Luiz Garcia em apoiar e ajudar de maneira concreta e efetiva a criação da Faculdade de Medicina, criando inclusive a Secretaria de educação, Cultura e Saúde para, sem prejuízo das suas múltiplas funções, exercer todo o seu prestigio e trabalho nesse particular. (GARCIA FILHO, 1960, p. 139).
\end{abstract}

Em setembro de 1966, ano de formatura da primeira turma, através do Decreto n. ${ }^{\circ} 59.226$, a Faculdade de Medicina de Sergipe obteve seu reconhecimento, transformando assim, mais que uma data, um símbolo para a comunidade sergipana. 


\section{CONCLUSÃO}

Diante da trajetória traçada da fundação e implantação da Faculdade de Medicina de Sergipe e a atuação de Antonio Garcia Filho na concretização desse projeto e sua participação no magistério e nas áreas política e social de Sergipe, podemos caracterizá-lo como um intelectual que, no bojo da História dos Intelectuais, na concepção de Sirinelli (1996, p. 232), se remete ao estudo de um grupo social. É um campo aberto e autônomo, "[...] situado no cruzamento das histórias política, social e cultural”. É neste campo que Garcia Filho se insere, enquanto intelectual de poder e influenciador social. Não hesitou em lançar esforços para contribuir com avanços nas áreas em que atuou, principalmente no campo da saúde.
Apesar de dificuldades operacionais e políticas da época, a Faculdade de Medicina de Sergipe foi uma obra que possibilitou, em 1968, a criação da Universidade Federal de Sergipe, pois o Estado contava apenas com cinco escolas de ensino superior que, por exigências legais, para que Sergipe pudesse pleitear a criação de uma Universidade seria necessário que a sexta escola de ensino superior fosse criada. Portanto, a Faculdade de Medicina de Sergipe desempenhou importante papel na educação do Estado, além de alcançar um dos principais objetivos almejados pelo grupo médico de Sergipe, a necessidade de formar médicos para atender a classe popular daquela época.

\section{REFERÊNCIAS}

BURKE, Peter. A revolução francesa da historiografia: a Escola dos Annales (1929-1989). São Paulo: Ed. UNESP, 1992. 153p.

CONDE GARCIA, Eduardo Antonio. Antonio Garcia Fitho e a faculdade de medicina de Sergipe: criador e criatura. Aracaju: SERCORE Artes Gráficas, 2008.

GARCES, Ednaldo A. A Faculdade de medicina de Sergipe - primeiros passos. In: Revista Somese, N. 125, (Setembro a Dezembro de 2011), p. 14-15.

GARCIA FILHO, Antonio. A reabilitação em Sergipe. Aracaju: Gráfica Aracaju, 1966.

LIMA, Jackson da Silva. Os estudos filosóficos em Sergipe. Aracaju: Sociedade Editorial de Sergipe. Vol.7. 1995. p. 66-71.
MAGALHÃES, Justino Pereira. Tecendo nexos: história das instituições educativas. Bragança Paulista/ Editora Universitária São Francisco, 2004.

NASCIMENTO E GALGANI- Histórica política de Sergipe: (1942-1955). 3. vol. Aracaju: Sociedade Editorial de Sergipe, 1999.

SANTANA, Antônio Samarone de. As febres do Aracaju: dos miasmas aos micróbios. São Cristóvão, Universidade Federal de Sergipe, 1997. (Dissertação de Mestrado).

SILVA, Henrique Batista. História da medicina em Sergipe. Editoração Eletrônica: Valfredo Avelino dos Santos, 2006.

SIRINELLI, Jean François. Os intelectuais. In: RÉMO- 
NO, René (Org.). Por uma história política. Tradução de Dora Rocha. Rio de Janeiro: Editora UFRJ/ Fundação Getúlio Vargas, 1996.

\section{FONTES IMPRESSAS}

FACULDADE DE MEDICINA DE SERGIPE. Ata de reunião do Conselho Técnico e Administrativo da Faculdade de Medicina de Sergipe, realizada no dia 21 de janeiro de 1960. Arquivo da Universidade Federal de Sergipe. CCBS (1954-1964), caixa 40, pacotilha 128.

FACULDADE DE MEDICINA DE SERGIPE. Ata de reunião da Congregação da Faculdade de Medicina de Sergipe, realizada no dia $1^{\circ}$ de fevereiro de 1961, no Instituto Parreiras Horta. Arquivo da Universidade Federal de Sergipe. CCBS (1954-1964), caixa 40, pacotilha 129.

FACULDADE DE MEDICINA DE SERGIPE. Ata de reunião da Congregação da Faculdade de Medicina de Sergipe, realizada no dia 19 de janeiro de 1962. Arquivo da Universidade Federal de Sergipe. CCBS (19541964), caixa 40, pacotilha 128.
SIRINELLI, Jean François. Elites Culturais. In: RIOUX, Jean Pierre. Por uma história cultural. Lisboa: Editora Estampa, 1997.

FACULDADE DE MEDICINA DE SERGIPE. Ata da sessão ordinária do Conselho Técnico Administrativo da Faculdade de Medicina de Sergipe. Arquivo da Universidade Federal de Sergipe. CCBS (1954-1964), caixa 40, pacotilha 129.

FACULDADE DE MEDICINA DE SERGIPE. Autorização para funcionamento da Faculdade de Medicina de Sergipe. Parecer n 679, de 12 de novembro de 1960. Arquivo da Universidade Federal de Sergipe. CCBS (1959-1967), caixa 01, pacotilha 01.

FACULDADE DE MEDICINA DE SERGIPE. Relatório de Verificação Procedida na Faculdade De Medicina de Sergipe. Arquivo da Universidade Federal de Sergipe. CCBS (1954-1964), caixa 40, pacotilha 129.
Recebido em: 13 de julho de 2012

Avaliado em: 24 de julho de 2012

Aceito em: 6 de agosto de 2012
1 Mestranda em Educação pela Universidade Tiradentes; Especialização em Psicomotricidade pela Faculdade Pio Décimo; Graduada em Educação Física pela Unit; Graduada em Gestão Pública pela Unit. Membro da Sociedade Brasileira de História da Educação; Membro do GPHPE(Grupo de Pesquisa História das Práticas Educacionais )/UNIT. Bolsista da FAPITEC-SE. E-mail: patriciasnsilva@hotmail.com

2 Doutora em Educação pela Universidade Federal do Rio Grande do Norte (UFRN); Mestre em Educação e bacharel em Ciências Sociais pela Universidade Federal de Sergipe (UFS). Professora PPG 1 da Universidade Tiradentes e líder do Grupo de Pesquisa Sociedade, educação, história e memória. E-mail: raylane_navarro@unit.br 